\title{
INCIDÊNCIA DA CARDIOPATIA CHAGÁSICA EM 15.000 NECRÓPSIAS CONSECUTIVAS E SUA ASSOCIAÇÃO COM OS "MEGAS" *
}

\author{
A. J. A. Barbosa $* *$ J. F. H. Pittella ** IV. L. Tafuri ***
}

\begin{abstract}
Os AA. estudaram a incidência da cardiopatia chagásica em 15.000 necrópsias consecutivas e sua associaça com os megas.

Em 875 cardiopatias chagásicas houve 145 casos de megas, ou seja, 16,56\%, com predominância do sexo masculino. No branco houve maior incidência (55) de megas do que no mulato (53) e no negro (31) dentre 858 cardiopatias chagásicas. Em 848 cardiopatias chagásicas, 85,78\% eram de individuos que faleceram entre 21 e 60 anos. O maior número de cardiopatias $(120$ ou 14,14\%) e de "megas" (21 ou 15,78\%) foi encontrado nos individuos entre 36 a 40 anos. Os nossos resultados mostram uma incidência diferente da associação cardiopaiia-mega, em comparação da observada em outras regiões do Pais e em outros paises da América do Sul.
\end{abstract}

Chapadeiro e cols. (4), estudando a incidência de "megas" associados à cardiopatia chagásica no Triângulo Mineiro, concluem pela existência de diferenças regionais nessa associação e admitem que as causas dessas diferenças necessitam maior investigação. De fato, os dados obtidos na literatura por Ramos (10); Jaffé (6); Nicola (8); Romana, Torres e Tornico (11); Baistrocchi (1); Brant e col. (2); Brant (3); Prata (9) e Köberle (7), demonstram a grande variaçāo da incidência de "megas" associados à cardiopatia chagásica.

Com a finalidade de ampliar os dados estatisticos já existentes, realizamos a presente pesquisa no sentido de verificar se também no nosso material (casos provenientes de várias regiões do Estado de $\mathrm{Mi}$ nas Gerais) a incidência de "megas" associados à cardiopatia chagásica é diferente da de outras regiōes do País. Por outro lado, foi possível também verificar qual a incidência de cardiopatia chagásica em 15000 autópsias realizadas no Departamen- to de Anatomia Patológica da Faculdade de Medicina da Universidade Federal de Minas Gerais.

\section{MATERIAL E MÉTODOS}

O material de estudo consta de 875 cardiopatias chagásicas crônicas de indivíduos provenientes em sua maior parte das regiões Norte, Nordeste, Centro e Centro-oeste do Estado de Minas Gerais, dentre 15000 autópsias realizadas no período de 1938 a 1966. O diagnóstico de cardite chagásica crônica foi feito, na grande maioria dos casos, baseado nos achados macro e microscópicos dos coraçōes. Nos casos mais antigos, o diagnóstico foi feito apenas pela análise histológica dos fragmentos do miocárdio

\section{RESULTADOS}

Os resultados estão resumidos nas tabelas I, II e III. Estão relacionados apenas

\footnotetext{
Trabalho do Departamento de Anatomia Patolólca (Prof. L. Bogliolo) da Faculdade de Medicina da UFMG.

Bolsistas da CAPES.

Prof. Adjunto.

Recebido para publicação em $3 / 3 / 70$
} 
os casos em que foram registrados o sexo, a côr e a idade, no protocolo de necrópsia. A tabela I mostra a incidencia da cardiopatia chagásica e dos megas, em relação ao sexo. Como se vê, há predominância no sexo masculino. O encontro, portanto, de 145 megas associados a 875 cardiopatias dá uma incidência de $16.56 \%$.

A tabela II mostra a incidência da cardiopatia chagásica e dos megas em relação à côr. No branco houve maior número de "megas" associados à cardiopatia chagásica do que no mulato e no negro. Estabelecendo-se a relação no de megas - n.o de cardiopatias, encontra-se no branco um caso de mega para 4 cardiopatias, no mulato $1: 7$ e no negro $1: 8$.

A tabela III mostra a incidência da cardiopatia chagásica e de "megas" em relação aos diferentes grupos etários. Nota-se que o maior número de cardiópatias e de "megas" foi encontrado no grupo etário de 36 a 40 anos. Foi menos freqüente no velho.

Do total de megas associados à cardiopatia chagásica, 59 eram megaesôfagos e 120 megacolos. Em 34 casos houve a associação megaesôfago-megacolo. Não foram constatados nos protocolos de necrópsia examinados casos de megaestômago, megaduodeno, megabexiga ou outros tipos de megas.

\section{COMENTÁRIOS}

Dentre as 15000 autopsias realizadas, 875 . ou seja. $5.83 \%$ eram de cardiopatas chagásicos crônicos. Excluindo, no entanto, os ratimortos e as crianças até 14 a:tos, o total de necrópsias realizadas fol de 7.126 . Assim sendo, a incidência de cardiopatia chagásica, no adulto, elevou-se pera $12.13 \%$ no nosso material. As percentagens assim obtidas são muito próximas às de Doehnert e Motta (5) na Venezuela, que encontraram para o total de necrópsias, incluindo os natimortos e crianças até 14 anos, $5.4 \%$ de cardiopatia chagásica, e no adulto, excluindo as crianças até 14 anos, $15.07 \%$.

Por outro lado, as nossas cifras são muito inferiores àquela encontrada $(41.82 \%)$ por Chapadeiro e col. (4) no adulto. A discrepância em relação aos dados de Chapadeiro e col. pode se explicar pelo fato de ser a zona do Triângulo Mineiro altamente endêmica, enquanto que o nosso material é proveniente de zonas diversas do Estado de Minas Gerais, inclusive das não endêmicas.

A associação "megas"-cardiopatia chagásica, no nosso material, foi de $16,56 \%$. Esta cifra é muito inferior à de Köberle (7), que encontrou em 250 chagásicos crônicos, 69 casos de megacolo, 62 casos de megaesôfago e 7 casos de gastromegalia, além de outros "megas". É próxima (17.3\%) da relatada por Chapadeiro e col. (4). Curioso notar que tanto Köberle quanto Chapadeiro trabalham em zonas muito próximas uma da outra. Qual seria, portanto, a razão de tão grande discrepância? Por outro lado, os nossos indices são bastante superiores em relação aos de Prata (9) na Bahia, que encontrou apenas $5.2 \%$ de associação. No Rio Grande do sul, Brant e col. (2) e Brant (3), e na Venezuela, Jaffé (6) não encontraram, até o momento, casos de megas associados à cardiopatia chagásica. Parece. portanto, não haver dúvidas de que a associação megas-cardiopatia chagásica é variável de região para região, como foi demonstrado por Chapadeiro e cols. (4).

\section{TABELA I}

INCIDENCTA DA CARDIOPATIA CHAGÁSICA E DOS "MEGAS", EM RELAC̣̃O AO SEXO 1 15.000 NECRÓPSIAS ?

\begin{tabular}{l|c|c|c|c}
\multicolumn{1}{c|}{ SEXO } & N. ${ }^{\circ}$ CARDIOPATIAS & $\%$ & N. DE MEAAS & DE \\
\hline MASC & 549 & 62.74 & 87 & 60,0 \\
FEM & 326 & 37,25 & 58 & 40,0 \\
\hline TOTAL & $875(5,83 \%)$ & & $145(0,96 \%)$
\end{tabular}




\section{TABELA II}

INCIDÊNCIA DA CARDIOPATIA CHAGÁSICA E DOS "MEGAS", EM RELAC̣Ã À CÔR

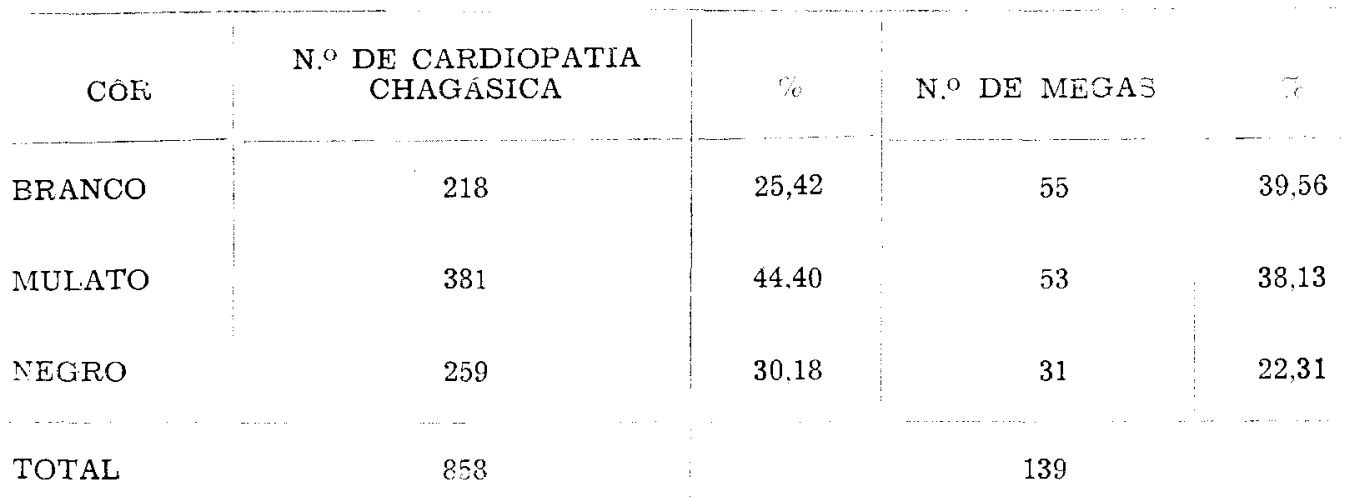

Inúmeros seriam os fatôres para explicar tal variação. Dentre êles poderiam ser ci-tados: - 1) cêpas diversas do Trypanosoma cruzi: até o momento, um de nós, $1 \mathrm{Ta}$ furi e col. (13), verificou que as cêpas "Y". Silva e Nussenweig (12), cêpas "PNM" e "ABC" apresentam comportamento diverso frente ao hospedeiro (camundongo), pois a cêpa " $\mathrm{Y}$ " é muito mais patogênica do que as cêpas "ABC" e "PNM"; 2) diferenças raciais: no nosso material houve maior associação de "megas"-cardiopatia chagásica no branco; (1:4) do que no mulato $(1: 7)$ e do que no negro $(1: 8) ; 3$ ) sexo: no nosso material houve maior incidência de mega e cardiopatia chagásica no sexo masculino; 4) meio ambiente; 5) dieta. Todos êsses fatôres, já citados por Chapadeiro e cols. (4), devem ser mais crofundamente analisados pois. a nosso ver, têm fundamento.

Quanto à incidência do tipo de "mega" encontrado verifica-se que no nosso material houve maior número de megacolo (120) do que megaesôfago (59). Em 34 casos de cardiopatia houve associação megaesôfagomegacolo. Comparando-se êstes dados com os de Chapadeiro (4) e os de Koberle (7). observa-se que no nosso material houve maior incidência $(2: 1)$ de megacolo em relaçāo ao megaesôfago do que o dos AA. referidos.

De acôrdo com os exposto na tabela III observa-se que $85.78 \%$ das cardiopatias chagásicas são de indivíduos que faleceram entre 21-60 anos. Doehnert e Motta (5), na Venezuela, no mesmo grupo etário, encontraram percentagem $(71,54 \%)$ pouco inferior à nossa.

Das 5.987 necrópsias realizadas em criancas de 0 a 14 anos, foram encontrados 7 casos de cardite chagásica, ou seja, $0,11 \%$. Doehnert e Motta, no mesmo grupo etário. encontraram $0,50 \%$

\section{$S U M M A R Y$}

The authors studied the incidence of chagasic cardiopathy in 15.000 consecutive necropsis and its asscciation with "megas".

There were 145 ocurrences of "megas" out of 875 chagasic cardiopathy $(16.56 \%)$ with the prominence of males. There was a greater incidence of "megas" in whites (55) rather than in mulattos (53) and in negroes (31) among 858 chagasic cardiopathy. In 848 chagasic cardiopathy, $85,78 \%$ were people who died between 21 and 60 years of age. The greatest number of cardiopathy (120 or 14.14\%) and "megas" (21 or 15,78\%) was found in individuris from 36 to 40 years of age. These results show a different incidence of ascociated cardiopathy and megas in comparison with those observed in other parts of the country and other countries in South America. 


\section{TABELA III}

INCIDENCIA DA CARDIOPATIA CHAGÁSICA E DOS "MEGAS", EM RELAC̣ĀO AOS GRUPOS ETÁRIOS

IDATE NO DE CARDIOFATA

0- 5

$6-10$

$11-15$

$16-20$

$21-25$

26-30

31-35

$36-40$

$41-45$

46-50

$51-50$

$56-60$

$61-65$

$66-70$

$71-75$

$76-80$

81-85

TOTAL
3

3

3

35

76

105

101

120

101

97

65

63

29

19

11

12

5

848
N. DE MEGAS

0,35

0,35

0.35

4,13

2

1.50

8.95

9

6.76

12.37

11

8,26

11,90

12

9,02

14,14

21

15,78

11,90

17

12,78

11.44

13

9,77

7.66

13

9,77

7.43

18

13,53

3,42

3,01

2,23

4,51

1.30

2,25

1,41

2,25

0,59

0,75 


\section{BIBLIOGRAFIA}

1 - BAISTROCCHI. J.D. Megacolon: Su tratamiento. El Dia Médico. 17: 476-478, 1945.

2 - BRANT, T. C.; LARANJA, F. S.: BUSTAMANTE, F.M. \& MELO, A.L. - Dados serológicos e eletrocardiográficos obtidos em populaçōes não selecionadas de zonas endêmicas de Doenca de Chagas no Estado do Rio Grande do Sul. Rev. brasil. malariol. doenças trop. 9: 141-147, 1957.

3 - BRANT, T.C. - Razōes para nova orientação nas pesquisas sôbre doencas de Chagas no Estado do Rio Grande do Sul. Rev brasil. malariol. doencas trop. 18: 105-112, 1966.

4 -. CHAPADEIRO, E.; LOPES. E.R.; MESQUITA, P.M. de \& PEREIRA, F.E.L. - Incidência de "megas" associados à cardiopatia chagásica. Rev. Inst. Med. Trop. Sãc Paulo. 6: 287-291, 1964.

5 -- DOEHNERT, H.R. \& MOTTA, G. Enfermedad de Chagas y miocarditis cronica. Archivos venezolanos de medicina tropical y parasitologia medica. Vol. V (1): 123-150, 1965.

6 - JAFFE, R. - Ùber Befunde an den Herzganglien bei Chagas-Myokarditis. Klin. Wschnschr. 39: 1083-1084, 1961.
7 - KöBERLE, F. - Patologic anatomy of enteromegaly in Chagas disease. Meeting of the Bockus Alumni International Society of Gastroenterology . 2: 92-110, 1962 .

8 - NICOLA, C.P. - El Megasigma. El Dia Médico. 20: 1125-1128, 1948 .

9 - PRATA, A. - Relação etiológica entre doença de Chagas e megaesôfago. Anais do Congresso Internarional sôbre a Doença de Chagas. 4: 1316-1336, 1963.

10 - RAMOS, J. - Moléstia de Chagas. Hospital (Rio de Janeiro). 58: 9-28, 1960 .

11 - ROMAÑA, C.; TORRES, A. \& TORNICO, R.A. - In Ramos, 1960.

12 - SILVA, L.H.P. da \& NUSSENWEIG, V. - Sôbre uma cêpa de Trypanosoma cruzi altamente virulenta para o camundongo branco. Folia Clinica et biol. 20: 191-207, 1953.

13 - TAFURI, W.L. \& BRENNER, Z. Lesões dos plexos de Meissner e Auerbach do intestino do camundongo albino na fase crônica da Tripanosomiase cruzi experimental. Rev. Inst. Med. trop. São Paulo. 9: 149-154, 1967. 